\title{
PRE AND POST-OPERATIVE DENTAL PAIN AND ANXIETY IN PATIENTS UNDERGOING ROUTINE DENTAL EXTRACTION, PESHAWAR
}

\author{
Najwa Karim ${ }^{1}$, Farooq Maqsood ${ }^{2}$, Kamran Khan ${ }^{3}$
}

\section{ABSTRACT:}

\section{OBJECTIVES:}

To determine the pre and post-operative dental pain intensity and dental anxiety in patients undergoing tooth extraction and providing counselling with dental treatments.

\section{METHODOLOGY:}

It was a comparative study conducted in dental hospitals of Peshawar i.e. Sardar Begum Dental College and Khyber College of Dentistry. A total of 200 participants were selected for this study through simple random sampling technique. Half of the participants $(N=100)$ received dental treatment with counselling, whereas half participants $(N=100)$ got only dental treatment. Informed consent was taken from the participants. Both genders having an age range of 18-60 years were included in the study. Those patients who have severe or other associated dental/medical problems were excluded from the study. Modified Wisconsin Brief Pain Questionnaire and Dental Anxiety Scale-Revised were used for data collection. Both questionnaires have high reliability and validity. The patients were counselled from time to time during the tooth extraction procedure to reduce their anxieties and divert their mind from dental tools and pain. The data was analysed using SPSS 22.0 version.

\section{RESULTS:}

The outcome of the study showed that the pain severity and dental anxiety was reduced in the patients taking dental treatment along with counselling after the dental extraction as compared to the patients having only dental treatment. Pain inference also improved after tooth extraction.

\section{CONCLUSION:}

Dentists should need to learn counselling skills to provide relief to patients from dental pain and anxiety. Patients suffering from dental pain or diseases also require some psychological interventions along with dental treatments.

KEYWORDS: Dental Extraction, Pain, Dental Anxiety, Anaesthesia, Counselling

How to cite this article:

Karim N, Maqsood F, Khan K. Pre and Post-Operative Dental Pain and Anxiety in Patients undergoing Routine Dental Extraction, Peshawar. J Gandhara Med Dent Sci. 2020; 7(1): 22-

https://doi.org/10.37762/jgmds.7-1.100 


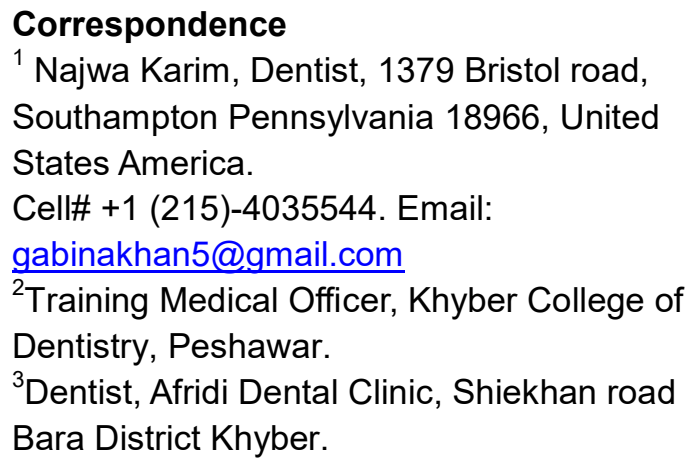

\section{INTRODUCTION:}

Tooth extraction or dental extraction is a process of pulling teeth from its socket (dental alveolus). Periodontal diseases, tooth decay and dental trauma are the common reasons for dental extraction especially when they are associated with toothache where restoration of teeth is not possible ${ }^{1}$. There are two types of dental extraction i.e. surgical and nonsurgical/simple. Post-extraction risks include swelling, pain, infection, bruising and bleeding. However, surgical post-extractions risks can be of high intensity, complicated and more painful. Anticoagulant drugs, prescribing antibiotics and evaluating the nerve damage risks are the predental extraction measures ${ }^{2}$. The dentists must manage post-extraction complications immediately to provide relief to the patients and minimize the risks of other dental problems ${ }^{3}$. The periodontal therapy aim is to improve the wellbeing of dental patients through maintaining the natural dentition in optimal conditions, whereas dental extraction is inevitable under certain circumstances that subsequently require the consideration of tooth replacement options ${ }^{4}$. Among them, fixed dental prostheses are regarded as a highly predictable and therapeutically versatile alternative, also associated with long-term patient quality of life. However, tooth or implant-supported cannot fully replace all the inherent functions and properties of natural teeth ${ }^{5}$. At dental hospitals mostly patients present with complaints of pain, which is a complicated and personal experience. People have different pain thresholds, which provide a basis for measuring the pain intensity. In dental clinical practice, assessment of pain is the routine procedure for which different tools are developed and dentists are using $i t^{6}$. The gold standard for measuring pain intensity is patient self-reports ${ }^{7}$. Most of the researches were done to minimize post-operative pain. Mostly non-steroidal antiinflammatory drugs, opioids and both are used to treat and control dental post-operative pain $^{8}$. Inflammation plays a vital part in wound healing and facial swelling or inflammation can lead to pain ${ }^{9}$. In dentistry anxiety and apprehension of fear can be seen by the patients in routine checkups. Almost 1/7 patients in western countries experience maximum anxiety during dental treatment ${ }^{10}$. The reasons can be due to the belief system of patients that they would have a painful experience ${ }^{11}$ and having a history of painful experiences during dental procedures $^{12}$. Oosterink et al, in their study, analyzed sixty-seven odonatological conditions, in $1^{\text {st }}$ place 
who stand out were due to anxiety of oral surgery whereas anxiety of dental extraction was in $5^{\text {th }}$ place ${ }^{12}$. Patients previous experiences helps to understand their state of anxiety, fear and pain. The patient having a maximum level of fear/anxiety will perceive and recall the treatment as more intense or painful as compared to patients having minimum anxiety or fear $^{13}$. The notion will reinforce that such patient will comply with treatment over time, primarily attainment of additional interventional treatments. In conservative treatments such as root canal treatment, patients are also found to have higher expectations of pain than they feel afterwards during treatment ${ }^{14}$. To the best of our knowledge, this is the first study that presents the analysis of pain experience before and after routine, uncomplicated tooth extraction with and without counselling. Everyone experience"s fear and anxiety before tooth extraction along with pain, anxiety not only produces emotional unease but may also provoke patient behavior that hinders procedure, in some cases prolonging the intervention and complicating postoperative pain ${ }^{15}$

\section{METHODOLOGY:}

A comparative research study was done to assess pre and postoperative dental pain in patients undergoing routine dental extraction and dental anxiety. It was conducted in the dental hospitals of Peshawar. The sample size was selected through simple random sampling method and a total of 200 patients participated in this study. 100 participants received dental treatment with counselling, whereas 100 participants were given only dental treatment. Informed consent was taken from the patients and welldeveloped questionnaires were used to collect the data i.e. Modified Wisconsin Brief Pain Questionnaire and Dental Anxiety Scale-Revised. Modified Wisconsin Brief Pain Questionnaire has two sub-scales; one is for measuring pain severity and second is to assess pain interference. The pain interference scales further evaluate the general activity, mood, walking ability, normal work, relations with other people, sleep and enjoyment of life. A pilot study was done on $10 \%$ of the population. SPSS version 22 was used for the analysis and interpretation of data. Paired sample t-test was done to analyze the data.

\section{RESULTS:}

Table 1 shows pre and post-operative dental treatment with and without counselling; as there is an evident difference between the means of dental severity with counselling and only dental treatment pre and postoperative dental extraction. In Table 2 , the pain inference was checked through rating their general activity, mood, walking ability, normal work, relations with other people, sleep and enjoyment of life. There was a significant improvement in the group having dental treatment with counselling as compared to other group having only dental treatment. In Table 3, dental anxieties in postoperative dental extraction in both 
groups were reduced but in group of was more evident. dental treatment with counselling it

Table 1: Pre and Post-Operative Dental Pain Severity Between the Two Groups

\begin{tabular}{|c|c|c|c|c|c|c|c|c|c|}
\hline & \multicolumn{2}{|c|}{$\begin{array}{l}\text { Pre-Pain } \\
\text { Severity }\end{array}$} & \multicolumn{2}{|c|}{$\begin{array}{c}\text { Post-Pain } \\
\text { Severity }\end{array}$} & \multirow[t]{2}{*}{$\mathbf{N}$} & \multirow[t]{2}{*}{$t$ (df) } & \multicolumn{2}{|c|}{$\begin{array}{c}\text { 95\% Confidence } \\
\text { Interval }\end{array}$} & \multirow[t]{2}{*}{$\begin{array}{c}\text { P- } \\
\text { value }\end{array}$} \\
\hline & Mean & SD & Mean & SD & & & Lower & Upper & \\
\hline DTC & 4.91 & 2.24 & 3.79 & 2.01 & 200 & $7.5(199)$ & .83 & 1.41 & $<0.001$ \\
\hline DT & 5.12 & 2.29 & 4.71 & 2.28 & & & & & \\
\hline
\end{tabular}

Table 2: Pain Interference of the Patients in Pre and Post-Operative Dental Pain

\begin{tabular}{|c|c|c|c|c|c|c|c|c|c|}
\hline & \multicolumn{2}{|c|}{$\begin{array}{c}\text { Pre-Pain } \\
\text { Interference }\end{array}$} & \multicolumn{2}{|c|}{$\begin{array}{c}\text { Post-Pain } \\
\text { Interference }\end{array}$} & \multirow[t]{2}{*}{$\mathbf{N}$} & \multirow[t]{2}{*}{$t$ (df) } & \multicolumn{2}{|c|}{$\begin{array}{c}\text { 95\% Confidence } \\
\text { Interval }\end{array}$} & \multirow[t]{2}{*}{$\begin{array}{c}\text { P- } \\
\text { value }\end{array}$} \\
\hline & Mean & SD & Mean & SD & & & Lower & Upper & \\
\hline "DTC & 5.03 & 2.50 & 3.60 & 2.00 & \multirow[t]{2}{*}{200} & \multirow[t]{2}{*}{$7.3(199)$} & \multirow[t]{2}{*}{1.04} & \multirow[t]{2}{*}{1.80} & \multirow[t]{2}{*}{$<0.001$} \\
\hline "DT & 5.23 & 2.49 & 4.07 & 2.48 & & & & & \\
\hline
\end{tabular}

Table 3: Dental Anxiety of Patients Before and After the Dental Extraction

\begin{tabular}{|c|c|c|c|c|c|c|c|c|c|}
\hline & \multicolumn{2}{|c|}{$\begin{array}{c}\text { Pre-Dental } \\
\text { Anxiety }\end{array}$} & \multicolumn{2}{|c|}{$\begin{array}{c}\text { Post-Dental } \\
\text { Anxiety }\end{array}$} & \multirow[t]{2}{*}{$\mathbf{N}$} & \multirow[t]{2}{*}{$t$ (df) } & \multicolumn{2}{|c|}{$\begin{array}{c}\text { 95\% Confidence } \\
\text { Interval }\end{array}$} & \multirow[t]{2}{*}{ P-value } \\
\hline & Mean & SD & Mean & SD & & & Lower & Upper & \\
\hline "DTC & 12.31 & 1.93 & 10.52 & 1.92 & 200 & $10.8(199)$ & 1.46 & 2.12 & $<0.001$ \\
\hline "DT & 12.46 & 1.92 & 12.09 & 2.23 & & & & & \\
\hline
\end{tabular}

DISCUSSION:

Dental anxiety and dental pain relationship must be well understood by the dentists, as this will have an impact on the quality of life of the patients after dental extractions. Most of the studies were centred around either pre or post-operative pain after careful removal of impacted third molars, or on the adequacy of various pharmaceutical agents in fighting pre and post-operative sequelae ${ }^{16}$. Successful management of the 
patient"s pain and anxiety is central to the practice of dentistry. The range of pharmacological and nonpharmacological techniques at the disposal of the dental clinician, all of which rely to some extent on the behavior management skills of the dental team includes local anaesthesia, conscious sedation, general anaesthesia, acupuncture, TENS (Transcutaneous Electrical Nerve Stimulation $)^{17}$. The National Institute for Health and Care Excellence (NICE) states that evidence-based psychological interventions such as Cognitive Behavioral Therapy can be effective treatments for anxiety related to dental pain and is recommended firstline treatments in preference to pharmacological treatment ${ }^{18}$. The intensity of dental anxiety towards dental pain is different among certain groups of population; several studies have shown that younger people, people with low income or socioeconomic status, and people with a low level of education tend to have more severe dental anxiety and pain than people who are elderly, more affluent or better educated ${ }^{19}$. Dental anxiety generally considered to have originated in childhood and develops further as a result of aversive conditioning and family influences ${ }^{20}$. The anxiety provoked the pain mostly by auxiliary treatment procedure involving aesthetic injection, sharp dental instrument, unpleasant sounds and vibration of the drill"s, experiences of the family members and friends, number of missing teeth may be an indicator of the number of traumatic experiences, fear of suffocation, claustrophobia, a sense of helplessness, visiting for the first time and minor oral surgical procedure like tooth extraction ${ }^{21}$. Moderate dental anxiety can be reduced by a pleasant dental environment, a calm atmosphere and a patient"s support attitude by medical staff, a trust relationship established through good communication between the patient and the doctor ${ }^{22}$. Certain information about the treatment procedure received from the practitioner would anticipate the sensation the patient might expect and see his preferences ${ }^{23,} 24$. An optimal preoperative counselling plan for the surgical extraction of a patient may have the greatest impact on preparing patients for extraction and may decrease the severity of pain ${ }^{25}$. Similar results were obtained in our study shown in Table 1. A study demonstrated that high pre-operative anxiety and stress levels could have an impact on post-operative recovery, resulting in increased post-operative pain $^{26}$. In Table 2, the group having dental treatment with counselling had minimized pain inference in postoperative dental extraction. A study in Korea found that patient selected music reduces the intraoperative anxiety during surgical extractions ${ }^{27}$. Similarly, in our study Table 3 shows that patients" dental anxiety significantly reduces when dental treatment is provided along with counselling as compared to only dental treatment. Another study conducted in Saudi Arabia reported that showing a dental extraction video to patients under local anaesthesia 
during the tooth extraction lowers the anxieties of the patients ${ }^{28}$

\section{CONCLUSION:}

Physical pain and diseases are interconnected with psychological disturbances. Most of the dental patients have dental anxieties and phobias due to which they resist dental treatment, so it is important for dentists to provide them comfort through utilizing counselling skills.

\section{LIMITATIONS:}

It was not a randomized control trial; patients" characteristics and dental treatments were varied from patient to patient. Pharmacological treatment effects were not observed in this study.

\section{REFERENCES:}

1. McCormick NJ, Moore UJ, Meechan JG. Haemostasis, part 1: the management of post-extraction haemorrhage. Dent Update. 2014;41(4):290-2, 294-6.

2. Nagraj SK, Prashanti E, Aggarwal $\mathrm{H}$, Lingappa A, Muthu MS, Krishanappa SKK, et al. Interventions for treating postextraction bleeding. Cochrane Database Syst Rev. 2018;3(3):CD011930.

3. Dodson T. Prevention and treatment of dry socket. Evid Based Dent. 2013;14(1):13-4.

4. American Academy of Periodontology. Comprehensive periodontal therapy: a statement by the American Academy of Periodontology. J Periodontol. 2011;82(7):943-9.

5. Ali Z, Baker SR, Shahrbaf S, Martin $\mathrm{N}$, Vettore MV. Oral health-related quality of life after prosthodontic treatment for patients with partial edentulism: a systematic review and meta-analysis. J Prosthet Dent. 2019;121(1):59-68.

6. Odai ED, Ehizele AO, Enabulele JE. Assessment of pain among a group of Nigerian dental patients. BMC Res Notes. 2015;8:251.

7. McCahon S, Strong J, Sharry R, Cramond T. Self-report and pain behavior among patients with chronic pain. Clin J Pain. 2005;21:223-31.

8. Gozali P, Kiattavornchareon S, Wu $\mathrm{M}$, Wonsirichat $\mathrm{N}$, Suphangul $\mathrm{S}$. Betamethasone and methylprednisolone usage in lower third molar surgery: review literature. M Dent J. 2015;35:27380.

9. Latt MM, Kiattavornchareon S, Boonsiriseth K, Pairuchvej V, Wongsirichat $\mathrm{N}$. The efficacy of dexamethasone injection on postoperative pain in lower third molar surgery. J Dent Anesth Pain Med. 2016;16:95-102.

10. Armfield JM, Heaton LJ. Management of fear and anxiety in the dental clinic: a review. Aust Dent J. 2013;58(4):390-407.

11. Tolvanen M, Hagqvist $O$, Luoto $A$, Rantavuori K, Karlsson L, Karlsson $\mathrm{H}$, et al. Changes over time in adult dental fear and correlation to depression and anxiety: a cohort study of pregnant mothers and fathers. Eur $\mathrm{J}$ Oral Sci. 2013;121(3pt2):264-9.

12. Oosterink FM, de Jongh $A$, Aartman $\mathrm{IH}$. Negative events and their potential risk of precipitating pathological forms of dental anxiety. J Anxiety Disord. 2009;23(4):451-7.

13. Levin L, Zini A, Levine J, Weiss M, Lev RA, Hai A, et al. Dental anxiety 
and oral health-related quality of life in aggressive periodontitis patients. Clin Oral Invest. 2018;22(3):1411-22.

14. Perkovic I, Romic MK, Peric M, Krmek SJ. The level of anxiety and pain perception of endodontic patients. Acta Stomatol Croat. 2014;48(4):258-67

15. Lago-Mendez L, Diniz-Freitas $M$, Senra-Rivera C, Seoane-Pesqueira G, Gandara-Rey JM, Garcia-Garcia A. Dental anxiety before removal of a third molar and association with general trait anxiety. $\mathrm{J}$ Oral Maxillofac Surg. 2006;64(9):14048.

16. Gozali P, Boonsiriseth K, Kiattavornchareon S, Khanijou M, Wongsirichat N. Decreased postoperative pain using a sublingual injection of dexamethasone $(8 \mathrm{mg}$ ) in lower third molar surgery. J Dent Anesth Pain Med. 2017;17(1):4753.

17. Hooten $\mathrm{M}$, Thorson $\mathrm{D}$, Bianco $\mathrm{J}$, Bonte B, Clavel Jr A, Hora J, et al. Pain: assessment, non-opioid treatment approaches and opioid management. Bloomington, $\mathrm{MN}$ : Institute for Clinical Systems Improvement: Updated 2017.

18. Appukuttan DP. Strategies to manage patients with dental anxiety and dental phobia: literature review. Clin Cosmet Invest Dent. 2016;8:35.

19. Yusa $H$, Onizawa $K$, Hori $M$, Takeda S, Takeda H, Fukushima $S$, et al. Anxiety measurements in university students undergoing third molar extraction. Oral Surg Oral Med Oral Pathol Oral Radiol Endod. 2004;98(1):23-7.

20. Thompson MW, Locker D, Poulton $R$. Incidence of dental anxiety in relation to dental treatment experience. Community Dent Oral Epidemiol. 2000;28:289-94.

21. Maytan LM, Terenzi GM. Fear and anxiety management for the special needs patient. Fearful Dent Patient. 2011:241-63.

22. Humud Rr, Walsh LJ. Dental anxiety: causes, complications and management approaches. J Minimum Intervention Dent. 2008;2(1):67-78.

23. Biggs QM, Kelly KS, Toney JD. The effects of deep diaphragmatic breathing and focused attention on dental anxiety in private practice setting. J Dent Hyg. 2003;77(2):105-13.

24. Hamasaki T, Soh I, Takehara T, Hagihara A. Applicability of both dentist and patient perception of dentist explanations to the evaluation of dentist-patient communication. Community Dent Health. 2011;28:274-9.

25. Taylor S, Kirton OC, Staff I, Kozol RA. Postoperative day one: a highrisk period for respiratory events. Am J Surg. 2005;190(5):752-6.

26. Liu R, Barry JE, Weinman J. Effects of background stress and anxiety on postoperative recovery. Anaesthesia. 1994;49:382-6.

27. Kim YK, Kim SM, Myoung $H$. Musical intervention reduces patients' anxiety in surgical extraction of an impacted mandibular third molar. $\mathrm{J}$ Oral Maxillofac Surg. 2011;69(4):103645.

28. Gazal G, Tola AW, Fareed WM, Alnazzawi AA, Zafar MS. A randomized control trial comparing the visual and verbal communication methods for reducing fear and anxiety during tooth extraction. Saudi Dent J. 2016;28(2):80-5. 


\section{CONTRIBUTORS}

Najwa Karim - Concept \& Design; Data Acquisition; Drafting Manuscript; Supervision; Final Approval

Farooq Maqsood - Concept \& Design; Data Acquisition; Drafting Manuscript

Kamran Khan - Data Analysis/Interpretation; Drafting Manuscript; Critical Revision

\section{(c) $(\Theta \odot$}

LICENSE: JGMDS publishes its articles under a Creative Commons Attribution Non-Commercial Share-Alike license (CC-BY-NC-SA 4.0). COPYRIGHTS: Authors retain the rights without any restrictions to freely download, print, share and disseminate the article for any lawful purpose. It includes scholarly networks such as Research Gate, Google Scholar, LinkedIn, Academia.edu, Twitter, and other academic or professional networking sites. 